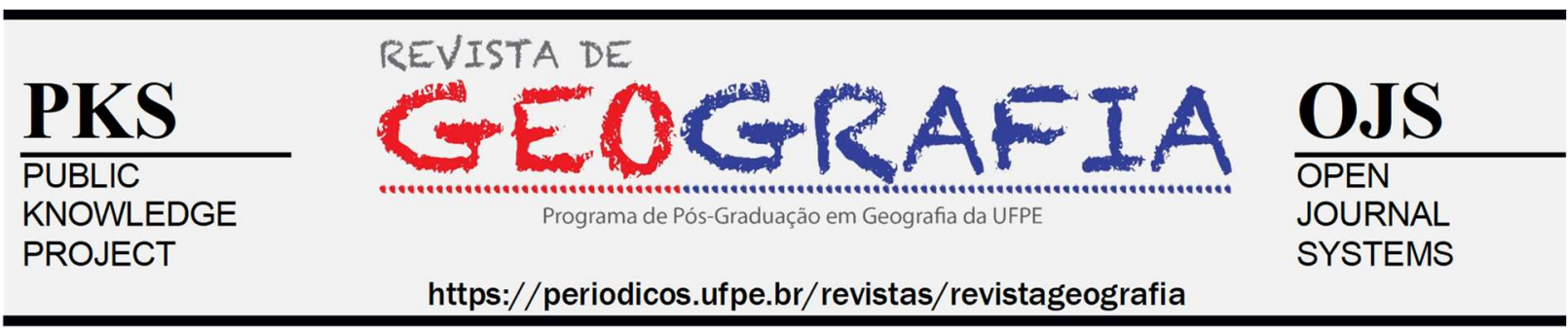

\title{
O ENSINO DE SOLOS NA MATÉRIA DE GEOGRAFIA COM ABORDAGEM EM EDUCAÇÃO AMBIENTAL: PROJETO SOLOS DO MEU BAIRRO
}

\author{
Paula Rayssa Dias Alves ${ }^{1}$, Murilo Noli da Fonseca ${ }^{2}$, Larissa Maria da Silva Ferentz ${ }^{3}$ \\ 1 Licenciatura em Geografia pela Universidade Federal do Paraná. E-mail: paula.rayssa.dias@gmail.com; \\ http://orcid.org/0000-0003-1905-4044 \\ ${ }^{2}$ Mestrando em Gestão Urbana pela Pontifícia Universidade Católica do Paraná. Especialista em Gestão Ambiental \\ de Empresas pela Faculdade. Bacharel em Geografia pela Universidade Federal do Paraná. E-mail: \\ murilonoli@gmail.com; http://orcid.org/0000-0002-0718-3087 \\ ${ }^{3}$ Doutoranda e Mestra em Gestão Urbana pela Pontifícia Universidade Católica do Paraná. Especialista em Gestão \\ Ambiental pelo Instituto Souza. Engenheira Ambiental pela PUCPR. E-mail: ferentzengenharia@gmail.com; \\ http://orcid.org/0000-0001-5804-0361
}

Artigo recebido em 05/06/2020 e aceito em 14/08/2020

\begin{abstract}
RESUMO
A finalidade desse trabalho é relatar a aplicação da prática pedagógica relacionada ao conteúdo de solos, como abordagem de Educação Ambiental em Geografia no Ensino Fundamental. As práticas foram realizadas com alunos do $9^{\circ}$ ano do Colégio Estadual São Sebastião, em Curitiba, Paraná. Foi elaborado um projeto nomeado Solos do Meu Bairro que visava a integração do tema Solo com a realidade e cotidiano dos alunos. O processo de ensino aprendizagem obteve três momentos: 1. aulas destinadas à teoria contando também com atividade e experimento, abordando os conteúdos básicos de solos adequados às turmas e sua faixa etária; 2. aula de campo no entorno do colégio com a finalidade de visualização na prática dos conceitos teóricos utilizando caderneta de campo como forma de avaliação da atividade extraclasse; 3. elaboração de maquetes com o tema uso e ocupação do solo em um bairro. Como resultado, os alunos apresentaram os produtos finais à comunidade escolar, na feira de ciências, por meio da aplicação do projeto como forma de Educação Ambiental.
\end{abstract}

Palavras-chave: Geografia; Uso e Ocupação do Solo; Educação Ambiental.

\section{SOIL TEACHING IN THE FIELD OF GEOGRAPHY WITH AN APPROACH TO ENVIRONMENTAL EDUCATION: THE SOIL PROJECT OF MY NEIGHBORHOOD}

\begin{abstract}
The purpose of this work is to report the application of pedagogical practice related to soil content, as an approach to Environmental Education in Geography in Elementary School. The practices were carried out with students of the 9th grade of Colégio Estadual São Sebastião, in Curitiba, Paraná. A project named Solos do Meu Bairro was designed to integrate the Solo theme with the students' reality and daily life. The teaching-learning process had three moments: 1 . classes aimed at theory, also counting on activity and experiment, addressing the basic contents of soils suitable for classes and their age group; 2 . field class around the school with the purpose of visualizing the practice of theoretical concepts using field notebooks as a way of evaluating extra-class activity; 3. development of models with the theme of land use and occupation in a neighborhood. As a result, the students presented the final products to the school community, at the science fair, through the application of the project as a form of Environmental Education.
\end{abstract}

Keywords: Geography; Land Use and Occupation; Environmental education. 


\section{INTRODUÇÃO}

A demanda por recursos naturais para manutenção do estilo de vida da sociedade moderna provoca diversos impactos sobre o meio ambiente. O uso excessivo sem a concepção da importância de conhecer e conservar os elementos da natureza forma cidadãos sem consciência ambiental e que contribuem negativamente na natureza. O solo, por exemplo, é um dos elementos que mais sofrem impactos, pois está amplamente exposto às fragilidades da ação antrópica. Consequência disso é a degradação dos solos que se traduz em desequilíbrios ambientais e perda de vida no ecossistema, algo que afeta espaços urbanos e rurais (CARVALHO e BARCELLOS, 2017; GUIMARÃES, et. al. 2012). Neste contexto a Educação Ambiental é um importante aliado das disciplinas escolares, pois visa favorecer a compreensão, por parte do aluno, de que ele próprio é membro integrante do ambiente e também agente ativo e passivo das transformações das paisagens terrestres, contribuindo assim para a formação de uma consciência conservacionista e ambiental não somente em seus aspectos naturais, mas também culturais, econômicos e políticos (BRASIL, 1997).

Conforme os Parâmetros Curriculares Nacionais (PCN) de geografia para Ensino Fundamental, de maneira geral, as pessoas têm uma atitude de pouca consciência e sensibilidade em relação ao solo, o que contribui para a sua degradação, seja pelo seu manejo inadequado ou pela sua ocupação desordenada. A percepção da importância do solo e da necessidade de sua conservação não faz parte do cotidiano das pessoas e isso contribui para o crescimento contínuo dos problemas ambientais ligados à degradação do solo (BRASIL, 1997).

Lima, Lima e Melo (2007) dissertam que apesar de sua importância, o espaço dedicado ao solo, no ensino fundamental e médio, é frequentemente nulo ou relegado a um plano menor, tanto na área urbana como rural. Este conteúdo nos materiais didáticos, muitas vezes, está em desacordo com os Parâmetros Curriculares Nacionais e, frequentemente encontra-se desatualizado, incorreto ou fora da realidade dos solos brasileiros. Além disto, este é, muitas vezes, ministrado de forma estanque, sem relacionar com a utilidade prática ou cotidiana desta informação, causando desinteresse tanto ao aluno quanto ao professor. Dentre outras, estas razões contribuem para que a população desconheça a importância e características do solo, o que expande o seu processo de alteração e degradação (FRAGOSO e NASCIMENTO, 2018).

Entende-se que o solo é de fundamental importância para os seres vivos, assim é necessário que desenvolva atividades nas escolas com este tema para que os alunos se sintam sensibilizados, e se preocupem com a sua conservação (GUIMARÃES et al., 2012). Diante 
disto, surge o projeto "Solos do Meu Bairro" que tem por finalidade estudar a função social e características dos solos na disciplina de Geografia como abordagem para Educação Ambiental. Este projeto atribui à importância de conhecer de forma mais aprofundada o solo e relacioná-lo com o espaço vivido pelo aluno a fim de estimular uma sensibilização quanto a conservação deste recurso. Esta iniciativa foi possível devido o PIBID ${ }^{1}$ (Programa Institucional de Bolsas de Iniciação à Docência) Geografia possibilitando a presença semanal em uma escola da rede pública. Assim, foram aplicadas aulas e atividades referentes ao tema solos no Colégio Estadual São Sebastião, localizado no Bairro Umbará em Curitiba (PR) (FIGURA 1).

Figura 1 - Localização do Colégio.
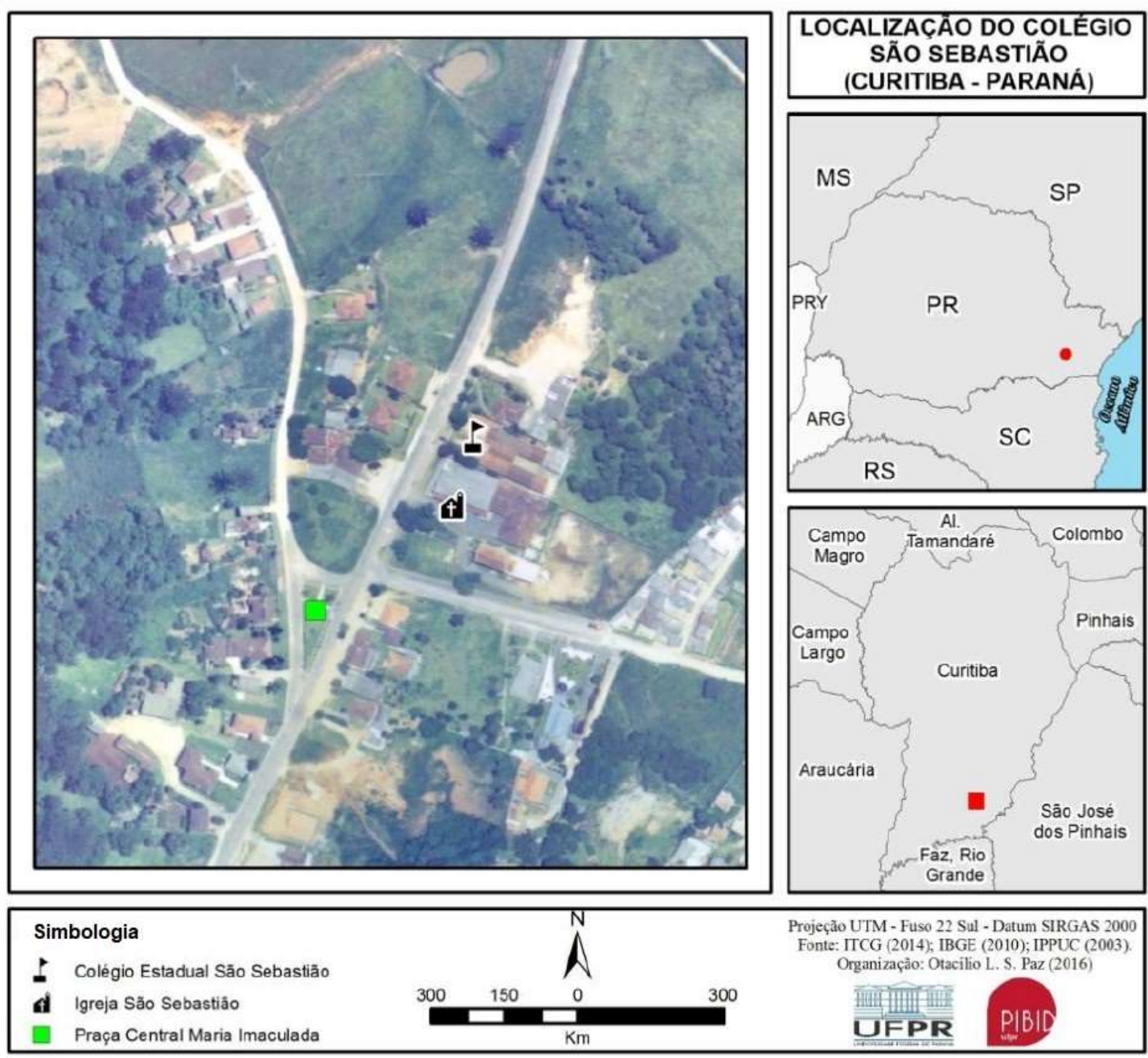

Fonte: os autores.

\footnotetext{
${ }^{1}$ É um programa de iniciação à docência aos alunos de cursos presenciais que se dediquem ao estágio nas escolas públicas e que, quando graduados, se comprometam com o exercício do magistério na rede pública. O objetivo é antecipar o vínculo entre os futuros mestres e as salas de aula da rede pública. Com essa iniciativa, o PIBID faz uma articulação entre a educação superior (por meio das licenciaturas), a escola e os sistemas estaduais e municipais (MINISTÉRIO DA EDUCAÇÃO, 2020).
} 


\section{REVISÃO DA LITERATURA}

A Educação Ambiental (E.A) surgiu como uma necessidade de mudança na forma de encarar o papel do ser humano no mundo. Os rumos da Educação Ambiental começam a ser realmente definidos a partir da Conferência de Estocolmo, em 1972, onde se atribuiu a inserção da temática da Educação Ambiental na agenda internacional. Em 1975, é lançado em Belgrado (Antiga Iugoslávia) a "Carta de Belgrado", que é resultado das discussões de estudiosos e especialistas de 65 países e se constituiu como documento que culminou na formulação de princípios e orientações para a criação de um programa Internacional em Educação Ambiental. Em 1977, aconteceu em Tbilisi, na Geórgia (ex-União Soviética), a Conferência Intergovernamental sobre Educação Ambiental. Foi deste encontro - firmado pelo Brasil - que saíram as definições, os objetivos, os princípios e as estratégias para a Educação Ambiental que até hoje são adotados (BEZERRA, 2007).

Apesar de ter assinado tal Conferência, o processo de institucionalização da E.A no governo federal brasileiro teve início em 1973 com a criação da Secretaria Especial do Meio Ambiente (Sema), vinculada à Presidência da República (PRONEA, 2014). Porém, a EA foi pela primeira vez citada na Constituição Brasileira em 1988 (inciso VI do artigo 225, do capítulo VI do Meio Ambiente) e foi formalmente instituída no país, pela lei federal de $\mathrm{n}^{\circ} 6938$, sancionada em 31 de agosto de 1981, quando foi criada a Política Nacional do Meio Ambiente (PNMA). Esta lei foi um marco histórico na institucionalização de defesa da qualidade ambiental brasileira. Foi também criado o Sistema Nacional do Meio Ambiente (SISNAMA) para possibilitar organicidade a todas as instâncias de ação principalmente governamentais. A Educação Ambiental no Brasil atingiu forte dinâmica nos anos 90, durante a Rio/92, no Fórum de Educação Ambiental, em Guarapari (ES) e I Conferência Nacional de EA (Brasília), ambas em 1997 (BEZERRA, 2007). A partir desses eventos a Educação Ambiental passou a ser regulamentada com a definição dos Parâmetros Curriculares Nacionais (PCN's) que estabelecem que os temas referentes ao meio ambiente devam estar presentes nos currículos de ensino sem constituir disciplina específica (BRASIL, 1997).

Segundo as Diretrizes Curriculares Nacionais para a Educação Ambiental, Art. $2^{\circ}$ entende-se que "a Educação Ambiental é uma dimensão da educação, é atividade intencional da prática social, que deve imprimir ao desenvolvimento individual um caráter social em sua relação com a natureza e com os outros seres humanos, visando potencializar essa atividade humana com a finalidade de torná-la plena de prática social e de ética ambiental". A Educação 
Ambiental é um processo de formação que, em si, precisa ser dinâmico, permanente e participativo, estimulando os estudantes quanto as suas responsabilidades e as do poder público (MALLMANN, CARNIATTO e PLEIN, 2020). Nesse processo, se faz necessário tornar as pessoas conscientes da importância de transformação do atual quadro em que o meio ambiente se encontra, reduzindo os impactos negativos para as gerações futuras (SILVA e OLIVEIRA, 2019).

Atualmente, a Educação Ambiental vem sendo incluída nos currículos escolares a partir de uma perspectiva de transversabilidade 2 . Os Parâmetros em ação Meio Ambiente da Escola, uma iniciativa vinda do Ministério da Educação (2007) por meio da Coordenação da Educação Ambiental, postula uma educação para uma Consciência Ambiental, a preservação e a conservação da natureza no marco da análise econômico-social dos problemas ambientais. Pode-se entender que a Educação ambiental permeia todas as disciplinas e se tratando de Educação Básica está presente desde os anos iniciais do Ensino Fundamental até Ensino Médio.

Conforme a Lei 9.795/99, ao inserir nas escolas a Educação Ambiental, busca-se articular os conteúdos das disciplinas corriqueiras com a sensibilização em prol da compreensão e consciência da importância de conhecer os elementos integrantes do meio ambiente e saber a ligação e interferência que as atividades da sociedade causam nesse meio. Em conjunto com outras disciplinas escolares, a Geografia pode ser uma ferramenta valiosa para elevar a criticidade ambiental dos alunos, pois nesta área é possível tratar de assuntos intrinsecamente polêmicos e políticos, quebrando a tendência secular da escola como algo tedioso e desligado do cotidiano. A temática ambiental insere-se como um dos desafios pedagógicos no ensino da Geografia, visto que cabe também à Geografia, juntamente com outras áreas do conhecimento, desenvolver nos educandos/as a capacidade de observar, analisar, interpretar e pensar com criticidade a realidade, tendo em vista sua transformação (BADR, 2017; SANTOS e CARVALHO, 2015; SILVA e OLIVEIRA, 2019).

No que se refere a temática Solos o trabalho integrado da disciplina Geografia com a Educação Ambiental são conjugados importantes que possibilitam o aprendizado da função social do solo e sensibilização quanto a questões de conservação e degradação desse recurso natural. Considerando-se que o solo é um componente do ambiente natural e humano, familiar

\footnotetext{
${ }^{2}$ Segundo o Ministério da Educação (2007), "são temas que estão voltados para a compreensão e para a construção da realidade social e dos direitos e responsabilidades relacionados com a vida pessoal e coletiva e com a afirmação do princípio da participação política. Isso significa que devem ser trabalhadas, de forma transversal, nas áreas e/ou disciplinas já existentes”. Os temas transversais, nesse sentido, correspondem a questões importantes, urgentes e presentes sob várias formas na vida cotidiana.
} 
e significativo para todos, ele pode ser um tema gerador na Educação Ambiental. No âmbito formal e informal, a abordagem pedológica é uma maneira de oportunizar a conscientização ambiental das pessoas, propiciando um conjunto de valores que as permitam perceberem, analisar e avaliar os impactos das ações públicas e privadas, assim como o impacto de suas próprias ações sobre o solo, e, portanto, sobre o meio ambiente (ARAÚJO e COSTA, 2015; CARVALHO e BARCELLOS, 2017).

De acordo com Arnoni (2003), o caminho possível para se trabalhar aspectos da temática ambiental, exigem que o ambiente não seja considerado como algo externo, distante e alheio ao homem, que as questões ambientais não sejam trabalhadas de forma fragmentada, a partir de ações disciplinadas e estagnadas, que as práticas pedagógicas não se destinem quase que, exclusivamente, a transmitirem os conhecimentos científicos. Assim, trabalhar os conteúdos de geografia como forma de Educação Ambiental permite aos alunos integrarem os conhecimentos presentes nos livros didáticos com sua realidade e os incita a se perceberem como agentes ativos ou passivos das transformações que ocorrem no meio ambiente.

\section{MATERIAIS E MÉTODOS}

Com o intuito de estudar o uso e ocupação do solo urbano na matéria de geografia como ensino de Educação Ambiental realizou-se aulas e atividades relacionadas ao tema para turma do $9^{\circ}$ ano do Ensino Fundamental. a educação formal, no âmbito do ensino fundamental e médio, por meio da Educação Ambiental, constitui-se em uma via importante para se despertar e ampliar a sensibilização em relação ao solo (CARVALHO; BARCELLOS, 2017; GUIMARÃES et al., 2012).

O primeiro passo foi preparar um plano para aplicação do Projeto Solos do Meu Bairro (QUADRO 1), um Plano de Aula para constituir metodologia de ensino do conteúdo de solos (QUADRO 2) e um campo de reconhecimento no entorno do colégio. O campo de reconhecimento foi efetuado para levantamento dos locais que poderiam conectar os conceitos de solos com a prática, para abordagem em aula de campo com os alunos. Silva e Oliveira Júnior (2016) ressaltam, que o trabalho de campo, assim como qualquer outra prática de ensino que promova a aprendizagem, precisa ser planejado, o professor precisa fazer um levantamento prévio de informações, esquematizar o roteiro, no intuito de evitar qualquer tipo de problema, e assim poder alcançar os objetivos da visita técnica com maior facilidade. 
Quadro 1 - Plano de projeto Solos do meu Bairro

\begin{tabular}{|c|}
\hline PLANO DE PROJETO \\
\hline $\begin{array}{l}\text { DISCIPLINA: Geografia } \\
\text { SÉRIE: } 9^{\circ} \text { ano do Ensino Fundamental } \\
\text { TEMA: Solos do Meu Bairro } \\
\text { TEMPO DE DURAÇÃO: } 5 \text { de maio a } 16 \text { de junho de } 2019-6 \text { aulas de } 45 \text { minutos cada (incluindo } \\
\text { experimento, produção e apresentação das maquetes); } 1 \text { campo de } 1 \mathrm{~h}: 30 \mathrm{~min} \text { no entorno do colégio. }\end{array}$ \\
\hline $\begin{array}{l}\text { JUSTIFICATIVA: Solo é um assunto pouco discorrido no Ensino Fundamental, as vezes ligado apenas } \\
\text { à matéria de ciências e sem relação com a realidade do aluno. Esse fato muitas vezes geral falta de } \\
\text { compreensão sobre a função do solo para a natureza e sociedade, suas características, as variedades, a } \\
\text { importância da conservação do mesmo e as degradações que ele pode sofrer, já que não é um recurso } \\
\text { renovável. Também pretende levar o aluno a ter um olhar mais geográfico para o lugar em que vive mais } \\
\text { especificamente ligado ao conteúdo de solos, sendo incentivado a perceber e avaliar os diferentes tipos } \\
\text { e usos. }\end{array}$ \\
\hline $\begin{array}{l}\text { OBJETIVOS: Fazer com que os alunos tenham uma base teórica sobre o conteúdo de solos. Realizar } \\
\text { atividade, experiências de campo e experimentos para que eles conheçam um pouco sobre o solo de seu } \\
\text { bairro e saiba identificar possíveis fatores que podem prejudicar esse recurso natural, a fim de sensibilizá- } \\
\text { los quanto à conservação dele e depois transferir para a comunidade do bairro Umbará por meio de } \\
\text { produção de maquetes. }\end{array}$ \\
\hline $\begin{array}{l}\text { AVALIAÇÃO: Serão cinco avaliações no total: relato de experimento com solo da residência dos } \\
\text { alunos que irá gerar um mapa; atividade de percepção do uso do solo no bairro; caderneta de aula de } \\
\text { campo e produção de produtos sobre uso e ocupação com enfoque nas maneiras de degradar/conservar } \\
\text { o solo em um bairro. }\end{array}$ \\
\hline $\begin{array}{l}\text { Dia 05/05 - Conhecendo o Umbará (Contextualizar o bairro que os alunos moram e/ou estudam) } \\
\text { Localização; Porque do nome; Histórico; Pontos mais conhecidos. }\end{array}$ \\
\hline $\begin{array}{l}\text { Dia 12/05 - Que solo é esse? } \\
\text { O que é solo?; Como o solo se forma?; Morfologia e Composição; Experiência e relato da prática com } \\
\text { solos da casa dos alunos. }\end{array}$ \\
\hline $\begin{array}{l}\text { Dia 19/05 - Usos do solo } \\
\text { Perfil do solo; Tipos; Degradação e conservação; Fertilidade; Pedir atividade de percepção do solo do } \\
\text { bairro (degradação e propor modos de conservação). }\end{array}$ \\
\hline $\begin{array}{l}\text { Dia 26/05 - Aula de Campo } \\
\text { Aula de campo com os alunos - identificar no campo os temas trabalhados em sala de aula; Caderneta } \\
\text { de campo; Tirar fotografias. }\end{array}$ \\
\hline Dia 09/06 - Produção da Maquete \\
\hline \\
\hline
\end{tabular}
Fonte: os autores.

Foi então encontrada uma propriedade próxima à escola, o local é um terreno que conta com a presença de um perfil de solo e seus horizontes bem aparentes, plantação de leguminosas utilizando adubo orgânico e um tanque que foi construído a partir de uma fonte natural contendo mata em volta para evitar o assoreamento. Também no entorno da escola foi localizado outra propriedade que tinha o solo com características de uso intenso e degradação. Dentre as opções encontradas a escolhida foi o primeiro terreno, pois o morador do local foi contatado e permitiu a visita dos alunos, ainda se dispôs a relatar suas técnicas de plantio e uso do solo. O ponto 
selecionado foi satisfatório, pois se encaixou na proposta de aula de campo e é um local conexo à realidade dos alunos.

Quadro 2 - Plano de Aula

\begin{tabular}{|l|}
\hline \multicolumn{1}{|c|}{ PLANO DE AULA } \\
\hline DISCIPLINA: Geografia \\
SEERIE: 9० ano do Ensino Fundamental \\
DURAÇÃO DA ATIVIDADE: 8 aulas de 45 minutos cada \\
CONTEÚDOS: Solos - Projeto Solos do Meu Bairro \\
\hline OBJETIVOS A SEREM ALCANÇADOS PELO ALUNO: compreender os conceitos básicos de solos a \\
partir da observação e experiência com o solo do bairro em que vivem/estudam (Umbará); relacionar teoria com \\
a prática; perceber a importância e utilidade do solo para a natureza e para a sociedade; se sensibilizar quanto \\
os fatores e ações que podem degradar e conservar o solo e transferir para a comunidade do bairro esse \\
aprendizado como forma de educação ambiental na feira de ciências. \\
\hline RECURSOS (MATERIAIS): Quadro negro, giz, slides em Power Point, pen drive, projetor, computador, \\
vídeos relacionados ao conteúdo, amostra de 3 tipos de rochas (sedimentar, metamórfica e ígnea), amostra de \\
solo, 1 saco plástico para cada aluno, recipiente com água, recipiente plástico, garrafa PET, colher, tesoura, \\
estilete, esponja de cozinha e guardanapo. \\
\hline PROCEDIMENTOS DIDÁTICOS: Realização de 8 aulos, sendo as 4 primeiras para exposição em Power \\
Point sobre conteúdo de solos relacionando com o bairro da escola juntamente com amostras e realização de \\
experimentos/atividades: histórico do bairro Umbará, o que é rocha, tipos de rocha, fatores que influenciam no \\
intemperismo, etapas da formação do solo, composição do solo, características e morfologia do solo, perfil e \\
horizontes do solo, degradação e conservação do solo, solos urbanos e rurais, alterações no solo e importância \\
da arborização. As outras 4 aulas foram divididas em: 2 de 45 minutos para realização da aula de campo no \\
entorno da escola; 1 aula de 45 minutos para construção da maquete; e 1 aula para exposição das maquetes para \\
os colegas de sala de aula.
\end{tabular}
Fonte: os autores.

O próximo passo foi realizar uma avaliação diagnóstica por meio de interpelação acerca do conhecimento dos alunos sobre o tema, para obter um panorama geral e assim averiguar se a intenção de apropriação do conteúdo estava adequada para o conhecimento já adquirido pela classe. Santos e Varela (2007) afirmam que um dos propósitos da avaliação com função diagnóstica consiste em informar o professor sobre o nível de conhecimentos e habilidades de seus alunos, antes de iniciar o processo de ensino. Para os autores o professor precisa, antes de tudo, verificar se seus alunos dominam, ou não, os pré-requisitos necessários para as novas aprendizagens, ou seja, se apresentam as habilidades e conhecimentos prévios necessários, sem os quais não poderão prosseguir para a próxima etapa. Portanto pode-se entender que avaliação diagnóstica “é uma etapa do processo educacional que tem por objetivo verificar em que medida 
os conhecimentos anteriores ocorreram e o que se faz necessário planejar para selecionar dificuldades encontradas" (SANTOS e VARELA, 2007, p. 4).

A partir dos resultados da sondagem foi possível preparar aulas em slides, utilizando bastantes imagens e vídeos para que se diversificassem as abordagens e por efeito permitir melhor compreensão. Para Zatta \& Aguiar, (2009) o trabalho do professor de Geografia precisa ser ancorado com ampla variedade de materiais que possibilitem planejar boas situações didáticas, possibilitando criar condições que permitam aos alunos progredir em suas aprendizagens sobre o mundo e suas vidas. Também ressaltam que filmes slides, programas de reportagem e imagens em geral podem ser utilizados para a problematização dos conteúdos de Geografia, desde que sejam explorados à luz de seus fundamentos teórica conceitual.

A organização das aulas e atividades sucedeu na seguinte configuração e sequência: foram utilizadas, no total, oito aulas de 45 minutos cada sendo quatro aulas teóricas sobre conteúdos básicos de solos e realização de um experimento; uma atividade de percepção do uso e ocupação do solo do trajeto de casa até a escola; trabalho de campo em duas aulas consecutivas; uma aula para produção de maquetes; uma aula para apresentação dos produtos cartográficos para a turma em sala de aula.

Na primeira aula expositiva dialogada foi trabalhado o bairro que os estudantes moram, a localização espacial, a origem do nome que está diretamente relacionado ao tipo de solo da região, histórico e identificação de alguns elementos principais do bairro para que se reconhecessem pertencentes ao lugar de estudo. É fundamental que o espaço vivido pelos alunos continue sendo o ponto de partida dos estudos ao longo do terceiro e quarto ciclos e que esse estudo permita compreender como o local, o regional e o global relacionam-se nesse espaço (BRASIL, 1997).

Nas aulas seguintes sucederam-se os conteúdos teóricos: o que é Solo, como se forma, sua morfologia, composição, perfil, tipos, degradação e conservação do solo urbano, sua relação com a paisagem, alguns tipos de solos presentes no bairro, Solo Urbano $x$ Solo Rural e fertilidade. Durante as aulas foi buscado fazer ligação com a realidade do aluno, teve-se a intenção de instigar o educando a perceber que o solo está presente no dia a dia, é onde ele pisa e exerce todas as atividades. O solo é um dos recursos naturais mais importantes, dele provém indiretamente a maior parte dos alimentos consumidos pela humanidade, além de ser suporte para a existência de boa parte da vida terrestre e manter o equilíbrio nos ecossistemas. Contudo na cidade esse recurso sofre consequências do intenso uso e ocupação para fins comerciais, 
industriais, de moradia, causando, por consequência, a degradação, quer seja pela contaminação por lixo; retirada de suas camadas; empobrecimento de nutrientes ou impermeabilização. (LIMA, LIMA e MELO, 2007).

Durante as aulas teóricas os alunos também fizeram um experimento (baseado em um experimento, que foi adaptado, do Programa Solo na Escola ${ }^{3}$ ) com o solo retirado do quintal de suas respectivas residências ou de um lugar próximo ao que moram e analisaram: cor, textura e consistência, elaborando um relato por escrito do que observaram seguindo um roteiro (QUADRO 3). Cada conceito solicitado no roteiro foi explicado e conforme houvesse necessidade os alunos recebiam acompanhamento individual. As amostras foram levadas pelos estudantes em um recipiente de plástico e para realizar a prática foram necessários os seguintes materiais: dois copos plásticos (um para água e outro para colocar o solo molhado) e guardanapo (para limpeza das mãos).

\begin{tabular}{|c|c|c|}
\hline \multicolumn{3}{|c|}{ Roteiro } \\
\hline \multicolumn{2}{|l|}{ Aluno: } & Professor: \\
\hline Turma: & Matéria: & Conteúdo: \\
\hline \multicolumn{3}{|c|}{ Qual a cor do solo? } \\
\hline \multicolumn{3}{|c|}{ Qual a textura do solo (areia, silte ou argila)? } \\
\hline \multicolumn{3}{|c|}{$\begin{array}{l}\text { Qual a consistência do solo (dureza - seco; friabilidade - úmido; plasticidade e } \\
\text { pegajoso - molhado)? }\end{array}$} \\
\hline \multicolumn{3}{|c|}{ Local em que o solo foi retirado: } \\
\hline
\end{tabular}

Também para complementar as aulas foram levadas amostras (FIGURA 2) de rochas, minerais e solos para que entendessem melhor, por meio da experiência, os conceitos de minerais, tipos de rochas e sua origem.

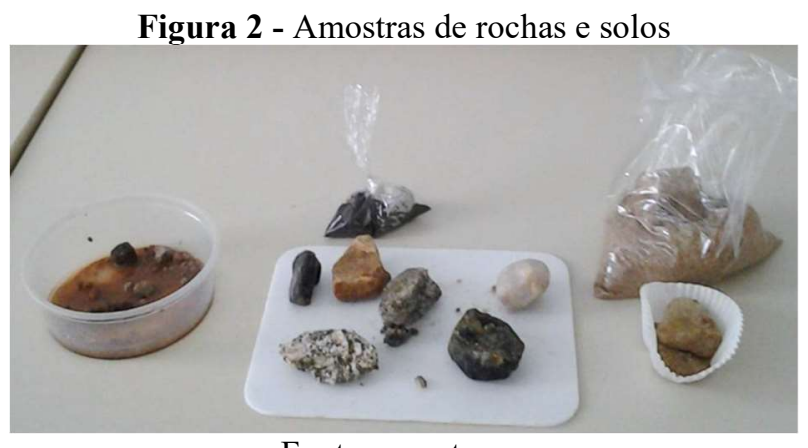

Fonte: os autores.

\footnotetext{
${ }^{3}$ O Programa de Extensão Universitária Solo na Escola é coordenado pelo Departamento de Solos e Engenharia Agrícola da Universidade Federal do Paraná. O objetivo geral deste projeto é promover, nos professores e estudantes do ensino fundamental e médio, a conscientização de que o solo é um componente do ambiente natural que deve ser adequadamente conhecido e preservado (UFPR, 2016).
} 
Foi solicitado que as turmas realizassem pesquisas de observação dos elementos da paisagem do seu cotidiano: no caminho de casa até a escola eles deveriam procurar locais em que o solo estava visivelmente degradado/poluído e assim anotar os elementos poluidores atuantes juntamente com o nome da rua. O objetivo dessa atividade era instigar os educandos a prestar atenção no espaço vivido e associar os elementos encontrados com os conteúdos. Para Silva e Oliveira (2019, p. 286) do ponto de vista da Geografia, essa atividade "permite compreender as relações entre homem e natureza e os processos de mudanças antrópicas, que modificaram de formas preocupantes os espaços naturais e sociais”. Segundo o Parâmetro Curricular Nacional de Geografia para os anos finais do Ensino Fundamental, o trabalho de observação da paisagem deve iniciar pelas características que mais tocam cada um. Uma mesma paisagem pode ser comunicada oralmente, textualmente ou em desenho, de forma distinta por cada pessoa que a tente representar. Isso reforça a ideia de que, quando se observa a paisagem, busca-se identificar os aspectos que fazem cada um se aproximar dela. Ainda conforme o PCN o professor pode também considerar as ideias diferentes e formar representação a partir da percepção que seus alunos têm sobre a representação do espaço. Os jovens e adolescentes têm maior autonomia em relação ao espaço, portanto sabem descrever os trajetos que percorrem, organizar um cômodo com seus móveis, ou representar esboços (croquis, desenhos) (BRASIL, 1997).

A aproximação entre os saberes cotidianos e os conteúdos estudados em sala de aula auxilia na compreensão dos alunos, podendo observar que o que estudam têm aplicação em suas vidas. Além disso, "contribui para aulas mais dinâmicas e construtivas, de modo que os discentes dialoguem com as situações vivenciadas no cotidiano e se sintam sujeitos da construção dos seus próprios conhecimentos" (MACÊDO, 2015, p. 6). Por isso, depois de encontrar os tipos de degradação eles deveriam apontar propostas de como conservar/recuperar esse solo; poderiam utilizar as soluções abordadas em sala de aula ou fazer pesquisas em bibliografias e/ou internet e depois apresentar seus resultados aos colegas.

Ainda foi realizada uma aula de campo, os alunos tiveram a oportunidade de visitar uma propriedade que apresenta alguns métodos de uso do solo. Segundo as Diretrizes Curriculares Estaduais de Geografia (2008), a aula de campo é um rico encaminhamento metodológico para analisar a área em estudo (urbano ou rural), de modo que o aluno poderá diferenciar, por exemplo, paisagem de espaço geográfico. Parte-se de uma realidade local, bem delimitada para investigar sua constituição histórica e as comparações com outros lugares, próximas ou 
distantes. Os estudos de paisagens urbanas e rurais, com toda a sua problemática, pode em grande parte ser desvendados pela observação direta dessas paisagens, assim uma excursão a um sítio ou a alguma fazenda garantirá um contato direto com o solo, a vegetação e as formas de organização da produção.

Assim a aula de campo foi um importante recurso didático para a finalização e compreensão do conteúdo, pois os estudantes observaram na prática o que viram em sala de aula e também puderam ampliar a compreensão dos conceitos por estar próxima a realidade deles. Conforme Silva e Oliveira Júnior (2016, p.1), a aula de campo permite "consolidar a teoria, trabalhada com livros didáticos em sala de aula. $\mathrm{O}$ contato com a realidade contribui no processo de ensino - aprendizagem na disciplina de geografia, pois proporciona a aprendizagem de temáticas essência".

O que mais chamou atenção no campo foi a recepção e discurso do proprietário do terreno, que enriqueceu o conhecimento sobre técnicas de plantio orgânico e sua visão de aproveitar o solo de maneira a causar menos impacto usando restos de frutas como adubo. Também, na ocasião, visualizaram um tanque de água mineral construído pelo anfitrião e assim observaram a importância da vegetação cercando o curso d'água com efeito de evitar assoreamento (FIGURA 3).

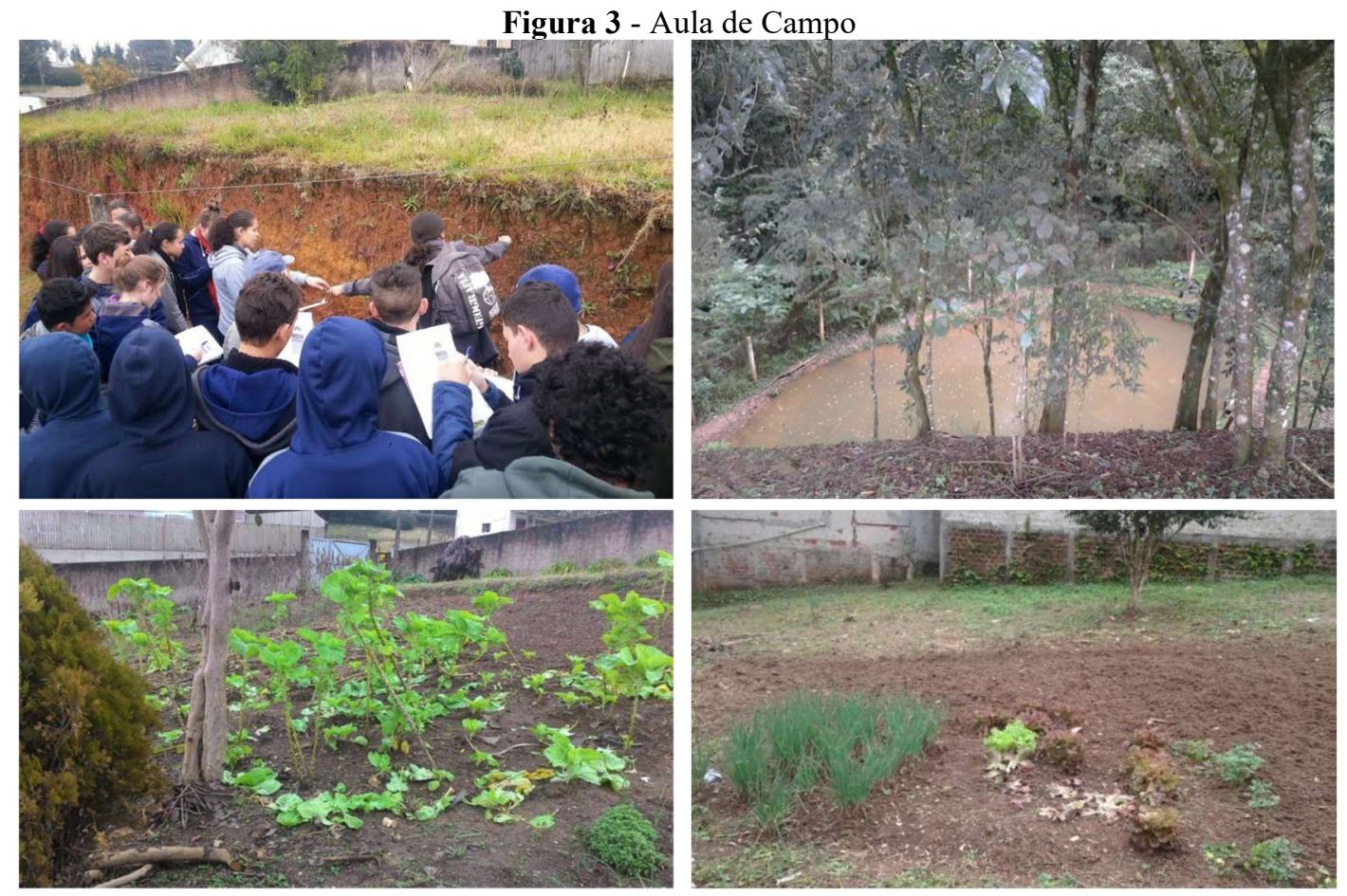

Fonte: os autores. 


\section{RESULTADOS E DISCUSSÕES}

Tendo em vista as atividades e aulas realizadas com os alunos onde possibilitam o aprendizado da temática solos com enfoque na educação ambiental, têm-se os seguintes resultados: atividade de percepção do solo do bairro, caderneta de campo (QUADRO 4) e maquetes de uso e ocupação do solo. Na primeira atividade, a de percepção do uso do solo no bairro, alguns estudantes desenharam um croqui dos pontos encontrados, outros tiraram foto exemplificando a degradação e explicando o processo ocorrido em um texto breve. Verificouse que a maioria dos alunos observou a presença de lixo e impermeabilização no solo e também propôs como redução do impacto a retirada do lixo, concomitante a sensibilização da comunidade sobre a importância de descartar os resíduos de forma adequada.

Quadro 4 - Caderneta de campo

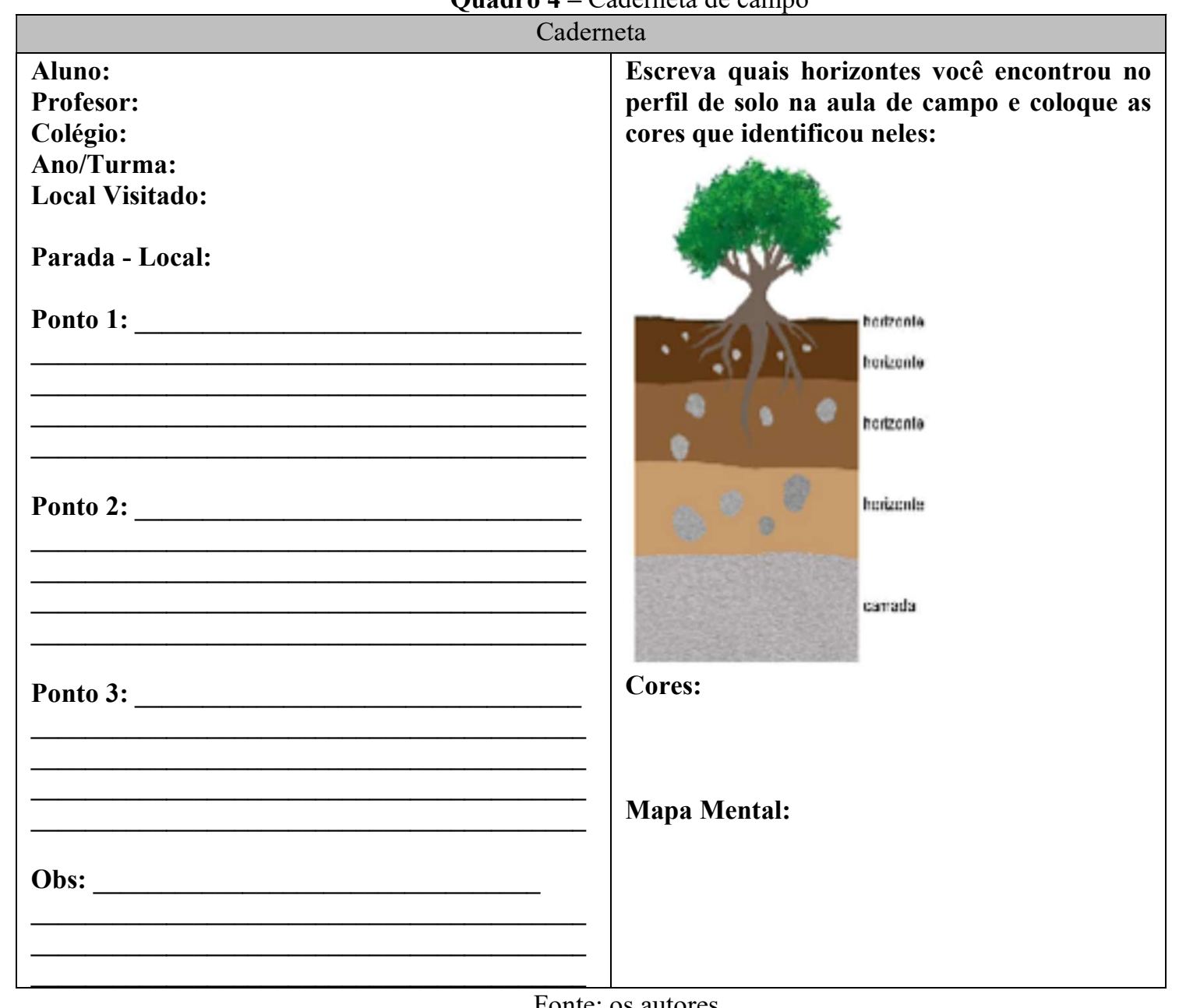

Fonte: os autores.

Também se notou que os alunos consideram importante a criação de áreas verdes para permitir a infiltração da água no solo e plantação de mais vegetação. A concepção dos 
estudantes está coerente com alguns autores, a exemplo de Londe e Mendes 2008), os quais concordam que as áreas verdes proporcionam benefícios para as pessoas e para a qualidade ambiental. Como exemplos de pontos positivos tem a minimização das ondas de calor, da poluição do ar, da poluição sonora e visual, assim como as melhorias na qualidade de vida da população, com espaços para lazer e recreação.

A terceira atividade, caderneta de campo, denotou um subsídio necessário para a aula de campo e foi elaborada a fim de ser um instrumento de norteamento, para que os estudantes observassem e anotassem os elementos que seriam tratados. Também foi utilizada como forma de avaliação, pois o desígnio do campo não foi realizar um passeio pelo entorno do colégio, mas ver na prática as teorias ensinadas. Materiais usados nas aulas de campo de Geografia como mapas e outras ilustrações impressas em tamanhos grandes (Formato A2 ao A0) e cadernetas de campo são extremamente úteis, "pois trazem ao aluno o sentimento/sensação de aula as atividades realizadas em campo, deixando de lado a impressão de ser mais um passeio da escola" (PAZ et al., 2015, p. 2).

A quarta atividade, elaboração de produtos, a princípio não foi planejada, apenas se deu a orientação para que os alunos pensassem no uso e ocupação do solo mais adequada para um bairro, considerando-o um recurso importante e por fim realizariam uma narração por escrito. Entretanto eles se dispuseram a construir maquetes, por isso ficou a critério deles a divisão dos grupos, a disposição das informações e a escolha do subtema. O objetivo de pensar e escrever sobre a ocupação de um bairro era avaliar se os alunos entenderam os conceitos ministrados e conseguiam descrever, mas o resultado foi melhor do que o esperado, pois eles concretizaram em seus trabalhos o conhecimento até então adquirido sobre degradação/conservação e uso e ocupação do solo. Por meio de uma maquete é possível ter uma maior interação entre a teoria e a prática, resultando em "aulas mais dinâmicas, que valorizem a criatividade, criticidade e atraiam o interesse" dos alunos (KUSMAN, 2015, p.41383).

Foram produzidas cinco maquetes com características próprias de acordo com a concepção de cada grupo acerca do tema estudado. Alguns destacaram a importância de se criar áreas verdes no espaço urbano, já outros ressaltaram os danos causados no solo urbano pela poluição de lixo, assoreamento, erosão pela retirada de vegetação e impermeabilização do solo.

A primeira maquete representa o uso do solo para fim urbano e segundo relato da dupla que elaborou o produto o enfoque é representar a degradação do solo por lixo e pastagem. A segunda maquete representa o uso do solo urbano que tem como finalidade conservar o solo 
por meio de áreas verdes, mantendo a mata ciliar em volta do rio e baixa densidade de construções. A terceira maquete aponta o uso do solo de forma organizada por lotes preservando a permeabilidade do solo nas propriedades. Enquanto que a quarta maquete expõe uso e ocupação do solo mais intenso, mas que mantêm a preservação de pequenas áreas verdes bastante mata ciliar para evitar erosão do solo. Por fim, a quinta maquete é uma representação com enfoque da degradação do solo. Contém uma plantação em forma de monocultura, solo exposto (devido retirada de vegetação), assoreamento do rio pela falta de mata ciliar e criação de animais que impacta o solo (FIGURA 4).

Figura 4 - Maquetes sobre conservação/degradação do solo elaborado pelos alunos do $9^{\circ}$ ano
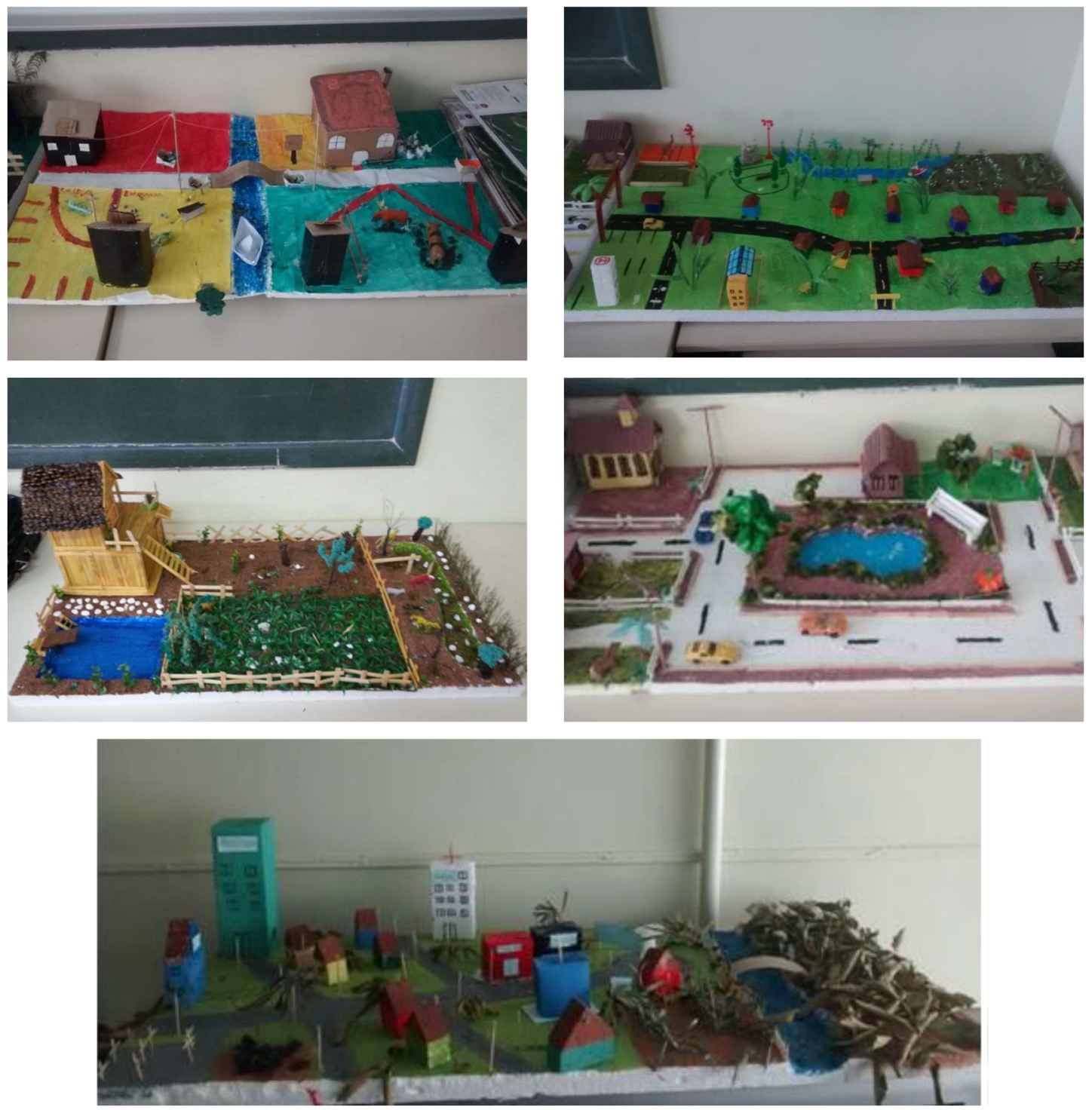

Fonte: os autores. 
No mês de outubro de 2019 foi realizado no Colégio Estadual São Sebastião a Feira de Ciências, destinada à comunidade escolar no dia da entrega dos boletins dos alunos. Os produtos, resultados de projetos e estudos dos alunos em todas as disciplinas, foram expostos nessa feira e visava a divulgação acerca dos conhecimentos adquiridos durante o trimestre. No que se refere ao projeto Solos do Meu Bairro, foram exibidas as maquetes produzidas pelos alunos para que os pais e visitantes vissem a produção e conhecimentos adquiridos por eles.

Não obstante, as atividades pedagógicas também se apresentam como importantes meios de aprendizagem para a percepção dos riscos associados ao mal uso e ocupação do solo devido ao processo de degradação presente nas cidades. A urbanização, por exemplo, tem aumentado a susceptibilidade dos solos aos agentes erosivos, a remoção da vegetação nativa, assim como, tem provocado a diminuição da qualidade dos córregos locais (MELO e ALMEIDA, 2013; MELO et al., 2018). Todos esses fatores foram observados pelos participantes, com maior intensidade dos que moram próximo a esses problemas.

Este tipo de percepção, dos problemas urbanos que cercam os locais de estudo, moradia e lazer, ajuda a formar um senso crítico nos alunos, de modo a se tornarem cidadãos com consciência da importância de um planejamento urbano sustentável (MELO e ALMEIDA, 2013). Deste modo, observou-se que as práticas pedagógicas obtiveram êxito, a adesão das aulas teóricas, experimentos, atividades de percepção do trajeto de casa até a escola e aula de campo foram envolvidos na construção das maquetes e também contribuiu como orientação de Educação Ambiental relacionado ao conteúdo de solos no ensino da geografia divulgados para a comunidade escolar.

\section{CONSIDERAÇÕES FINAIS}

Diante das aulas e práticas realizadas com a turma do $9^{\circ}$ ano do Ensino Fundamental percebeu-se que é importante o professor trabalhar com mais profundidade os conteúdos relacionados ao meio ambiente e procurar relaciona-lo com o convívio do aluno, se apropriando também de metodologias diferenciadas para que as possibilidades de aprendizado sejam diversificadas. Para tanto, o estudo do solo, como matéria de educação ambiental na disciplina de geografia, se mostra necessário para compreensão da necessidade de evitar a deterioração desse recuso natural. Trazer a consciência dos processos de formação, uso e ocupação do solo permitiu aos estudantes repensarem suas posturas frente às práticas diárias que podem ser determinantes para a manutenção dos elementos da natureza, neste caso específico o "solo". 
Guimarães et al. (2012) afirma que para se transmitir o valor do recurso natural solo é necessário que o aluno tenha uma experiência pessoal com o mesmo; no processo de aprendizado dos alunos, estes deve obter experiência prática que o leve a construir o conhecimento sobre a importância da conservação do solo e caracterizar a relação das atividades humanas e a manutenção do ecossistema terrestre. Deste modo, trabalhar com conceitos aliados a experimentos, atividades de observação, relato, síntese; realizar aula de campo tendo como apoio para anotação caderneta de campo e elaboração de produtos cartográficos foi eficaz no processo de ensino e aprendizagem. Também apresentar para a comunidade escolar as maquetes produzidas se encaixou no objetivo de não deixar apenas dentro da escola o aprendizado e resultados dos alunos, mas se estendeu para toda a comunidade escolar o conhecimento a fim de sensibilizar quanto a magnitude dos impactos da degradação do solo e as atitudes de conservação, incitando a se perceber cada indivíduo como agente importante nesse processo, mesmo que suas contribuições sejam mínimas mas que em conjunto causam danos.

Apesar da importância do solo para a sociedade e a natureza o que se nota é que o estudo deste recurso, muitas vezes, não é muito trabalhado de maneira clara em sala de aula com alunos e quando é muitas vezes é citado (principalmente em livros didáticos) como algo distante ou com defasagem; e este trabalho procurou desconstruir tal abordagem.

\section{AGRADECIMENTOS}

O presente trabalho foi realizado com apoio da Coordenação de Aperfeiçoamento de Pessoal de Nível Superior - Brasil (CAPES) - Código de Financiamento 001.

\section{REFERÊNCIAS}

ARAÚJO, F. H; COSTA, D.F. da S. Solo Na Educação Ambiental: como proposta para o ensino fundamental e médio. CERES, v. 1, n. 2, p.1-4, 2015.

BERGAMASCO, A.M. A aula de campo e suas contribuições no estudo dos solos em Geografia. Cad. PDE, Curitiba, v.2, p.2-36, 2013.

BEZERRA, A.A. Fragmentos da história da Educação Ambiental (EA). Rev. Ele. da Faced, v.1, n.3, p.1-06, 2007. 
BRASIL. Parâmetros Curriculares Nacionais: Geografia. Secretaria de Educação Fundamental, Brasília, 1997. 156p.

CARVALHO, N.L. de.; BARCELLOS, A.L. de. Educação ambiental: importância na preservação dos solos e da água. REMOA, v. 16, n. 2, p. 39 - 51, 2017.

FIGUEIREDO, V.S. SILVA, G.S.C. A importância da aula de campo na prática da Geografia. In: X Encontro Nacional de Prática de Ensino de Geografia, Porto Alegre, 2009. Anais... X Encontro Nacional de Práticas de Ensino de Geografia, Porto Alegre, v.2, p.1-09, 2009.

FRAGOSO, E.; NASCIMENTO, E. C. M. A Educação Ambiental no Ensino e na Prática Escolar da Escola Estadual Cândido Mariano - Aquidauana/MS. Amb. \& Ed., v. 23, n. 1, p. 161-184, 2018.

GUimarÃES, M.A., CRISTO, S.S.V., PAIXÃO, R.B., SANTIAGO, A.M.A. Educação Ambiental: nossos solos, nossa vida. Rev. Ed. Amb., Novo Hamburgo, n.41, p.1-11, 2012.

KUSMAN, R.A. Utilização de Maquetes como Recurso de Ensino em Educação Ambiental nos $6^{\circ}$ Anos. In: XII Congresso Nacional de Educação, Curitiba, 2015. Anais... XII EDUCERE, Curitiba, p. 41378-41385, 2015.

LIMA, V.C, LIMA, M.R de; MELO. V.F. O solo no meio ambiente: abordagem para professores do ensino fundamental e médio e alunos do ensino médio. Curitiba: Universidade Federal do Paraná, Departamento de Solos e Engenharia Agrícola, 2007. 130 p.

LONDE, P.R., MENDES, P.C. A influência das áreas verdes na Qualidade Urbana. Rev. Bras. de Geo. Médica e da Saúde, Rio de Janeiro, v.10, n.18, p.264-272, 2014.

MACÊDO, H.C. Refletindo sobre o espaço vivido: o lugar na construção dos conhecimentos geográficos. Rev. Bras. de Ed. em Geo., Campinas, v.5, n.10, p.152-165, 2015. 
MALlmANN, A.; CARNIATTO, I.; PLEIN, C. A. Educação Ambiental do Ponto de Vista das Concepções de Desenvolvimento Sustentável na Escola do Campo. Revbea, São Paulo, v. 15, n. 1, p. 44-61, 2020.

MELO, F.P.; ALMEIDA, J.P. Crescimento Urbano Desordenado e seus Reflexos nas Encostas dos Vales de Garanhuns-PE. Revista Científica ANAP Brasil, Tupã, v. 6, n. 7, p. 40-65, 2013.

MELO, F.P.; GOIS, D.V.; SANTOS, C.A.; SOUZA, R.M.; GUERRA, A.J.T. Estruturação de Modelo de Risco de Degradação Ambiental aplicado ao Município de Pacatuba-SE. Caderno de Geografia, Poços de Caldas, v. 28, n. 54, p. 674-685, 2018.

MINISTÉRIO DA EDUCAÇÃO. Parâmetros Curriculares Nacionais: introdução aos Parâmetros Curriculares Nacionais. Brasília, 2007.

PIBID. Brasília, 2020. Disponível em: http://portal.mec.gov.br/pibid. Acesso em: 05 jun. de 2020.

PARANÁ. Diretrizes curriculares estaduais de geografia para a educação básica. Curitiba, 2008.

PAZ, O.L.S.; OLIVEIRA, A.A.; SILVA, C.T.; HIRAOKA, D.A.; PEGORETTI, R.F. Caderneta de campo: importante material didático para as aulas de campo de Geografia. Curitiba: UFPR, 2015.

SANTOS, C. A maquete da Baixada Santista no ensino de Geografia: teoria e prática. Revela, Praia Grande, n.6, p.1-10, 2010.

SANTOS, M.R da; VARELA, S. A Avaliação como um Instrumento Diagnóstico da Construção do Conhecimento nas Séries Inicias do Ensino Fundamental. Rev. Ele. de Ed., n. 1, p.1-25, 2007. 
SANTOS, R.M. dos; CARVALHO, A.G.B.M. de. Geografia e Educação Ambiental: Percepção dos Professores sobre o uso da Geografia como Ferramenta para a Educação Ambiental em Birigui-SP. Geoambiente On-line, n. 25, p. 103-117, 2015.

SILVA, A.F. da; OLIVEIRA JÚNIOR, R.J. de. Aula de Campo como Prática de Ensino Aprendizagem: Sua Importância para o Ensino da Geografia. In: XVIII Encontro Nacional de Geógrafos, 2016, São Luis. Anais... XVIII Encontro Nacional de Geógrafos, São Luis, 2016, p.1-10.

SILVA, W.I.; OLIVEIRA, J.G.R. de. Práticas de Educação Ambiental nas Aulas de Geografia do Ensino Médio: Reciclando Velhos Hábitos. Revbea, v. 14, n. 1, p. 275-294, 2019.

UFPR. Programa Solo na Escola. Curitiba: UFPR, 2016. Disponível em: http://www.escola.agrarias.ufpr.br/index_arquivos/sobre.htm. Acesso em: 15 jan. 2020.

ZATTA, C.I.; AGUIAR, W.G. O uso de imagens como recurso metodológico para estudar Geografia. Dia a Dia Educação, 2009. Disponível em: http://www.diaadiaeducacao.pr.gov.br/portals/pde/arquivos/2375-8.pdf. Acesso em: 26 mar. 2020. 